\title{
Medical Treatment of Ankylosing Spondylitis
}

\author{
Kyoung-Ho Moon, MD, PhD, Young-Tae Kim, MD \\ Department of Orthopedic Surgery, Inha University School of Medicine, Incheon, Korea
}

The diagnosis of ankylosing spondylitis is often delayed due to ambiguous clinical manifestations and strict diagnostic criteria. However, imaging techniques such as magnetic resonance imaging have been found effective for the early diagnosis of non-radiographic sacroiliitis. New tumor necrosis factor alpha (TNF- $\alpha$ ) inhibitors have good efficacy for patients with persistently high disease activity despite conventional nonsteroidal antiinflammatory drug treatment. Thus, early diagnosis and aggressive treatments are essential for ankylosing spondylitis patients. Because many patients complain of musculoskeletal pains, especially around the sacroiliac joint area, hip specialists should be informed of up-to-date knowledge. In this review, we discuss new diagnostic criteria for ankylosing spondylitis, administration methods of TNF- $\alpha$ inhibitors, and the long-term follow-up results for patients treated with TNF- $\alpha$ inhibitors.

Key Words: Ankylosing spondylitis, Medical treatment, TNF- $\alpha$ inhibitors

\section{INTRODUCTION}

Ankylosing spondylitis is a chronic disease that involves sacroiliac joints as well as spine/pelvic limb joints and eventually causes deformity and ankylosis of the spine and joints ${ }^{1)}$. The disease often involves the hip and shoulder joints, and surgical treatments are required if severe joint contracture is found. Accurate assessment of the range of hip movement is critical for better understanding of disease progression considering that $1 / 3$ of the patients present symptoms in the hip. Both

Submitted: July 5, 2014 1st revision: July 28, 2014

2nd revision: August 28, 2014 Final acceptance: September 3, 2014

Address reprint request to

Kyoung-Ho Moon, MD, PhD

Department of Orthopedic Surgery, Inha University Hospital,

7-206, 27 Inhang-ro, Jung-gu, Incheon 400-711, Korea

TEL: +82-32-890-3663 FAX: +82-32-890-3047

E-mail: moondinha.ac.kr

This is an Open Access article distributed under the terms of the Creative Commons Attribution Non-Commercial License (http://creativecommons. org/licenses/by-nc/3.0) which permits unrestricted non-commercial use, distribution, and reproduction in any medium, provided the original work is properly cited. sides of the hip joints may be involved, which makes them more vulnerable and they often present more serious damage than other joints. Flexion contracture of the hip joint, mostly found in the advanced stage of the disease, results in rigid gait with knee joint flexion in order to maintain a standing posture. In contrast, ankylosing spondylitis involves other organs and affects the life quality of patients via accompanying dactylitis (25-50\%), uveitis (25-40\%), inflammatory bowel disease $(26 \%)$, and psoriasis $(10 \%)^{2}$. Although the etiology of the disease is yet to be elucidated, human leukocyte antigen (HLA) B27 is one of the most important factors; the prevalence rate of HLA-B27positive patients ranges from $0.4 \%$ to $1.4 \%$ depending on patients' ethnicity ${ }^{3)}$. The onset of ankylosing spondylitis occurs mostly between the ages of 20 to 30 years; its diagnosis can be delayed by 5-6 years ${ }^{4}$.

So far, ankylosing spondylitis has been diagnosed mainly on the basis of the modified New York criteria ${ }^{1}$. However, development of new diagnostic criteria is warranted because early detection of inflammation in the sacroiliac joint is now possible through advanced diagnostic technologies (e.g., magnetic resonance imaging $[\mathrm{MRI}]$ ). Such early detection of inflammation is 
impossible through x-ray examinations; yet, detection of abnormalities in the sacroiliac joint by $\mathrm{x}$-ray examinations is essential to meet the modified New York criteria ${ }^{1}$. In addition, since an innovative early treatment approach using potent biological agents has been introduced, development of new diagnostic criteria became an important issue ${ }^{5)}$. Recognizing this need, the ASsessment of Ankylosing Spondylitis (ASAS), a group of experts in ankylosing spondylitis, provided diagnostic criterion and treatment guidelines in $2010^{6}$.

The most common early symptom of ankylosing spondylitis is pain in the sacroiliac joint; in many cases, patients visit clinics for consultations with hip joint specialists in the early stage of the disease, since they understand that early diagnosis and medication would be critical. Therefore, in the present study, the authors would like to introduce a new diagnostic criterion as well as treatment guidelines in addition to the recent use tumor necrosis factor alpha (TNF- $\alpha$ ) inhibitors and describe long-term follow-up results of TNF- $\alpha$ inhibitors, which would be useful for hip joint specialists who treat ankylosing spondylitis patients.

\section{DIGNOSIS AND MEDICAL MANAGEMENT OF ANKYLOSING SPONDYLITIS}

Ankylosing spondylitis occurs 2-3 times more frequently in males and disease presentations differ between male and female patients. In male patients, the spine and pelvis are the most vulnerable sites and present serious symptoms. In contrast, in female patients, spine is rarely affected, whereas knees, wrists, and hips are the major sites ${ }^{7}$. Given these differences between the sexes and the requirement of confirmation of inflammation in the sacroiliac joint by $\mathrm{x}$-ray results to fulfill the modified New York criteria, the average time from the appearance of symptoms to diagnosis may be $>10$ years for female patients ${ }^{8}$.

Modified New York criteria include three clinical diagnostic criterion and a radiological diagnostic criterion; the diagnosis of ankylosing spondylitis requires the radiological criterion and at least one of clinical criterion implemented (Fig. 1). The radiological criterion only includes an increase in inflammation of the sacroiliac joint observed in x-ray images. However, a recent report indicated that MRI is able to detect sacroilitis on average 7.7 years earlier than x-ray imaging, indicating that the modified New York criteria may not be suitable for early detection". Furthermore, even though spondyloarthritis does not meet the modified New York criteria, the disease burden is similar to that of ankylosing spondylitis and both diseases exhibit favorable clinical outcomes in response to recently developed biological agents, emphasizing the necessity of new diagnostic criteria ${ }^{10,11}$.

\section{Diagnostic Criteria for ASsessment of Ankylosing Spondylitis (ASAS) ${ }^{6)}$}

Due to the limitations of conventional modified New York criteria and the need for early detection and diagnosis, a wider term, axial spondyloarthritis, is now used instead of ankylosing spondylitis so that early diagnosis can be made if there are clinical symptoms and MRI findings but no

- Clinical criteria:

- Low back pain and stiffness for more than 3 months that improves with exercise, but is not relieved by rest.

- Limitation of motion of the lumbar spine in the sagittal and frontal planes.

- Limitation of chest expansion relative to normal values correlated for age and sex.

Radiological criterion:

- Sacroiliitis grade $\geqslant 2$ bilaterally or grade 3-4 unilaterally. Definite AS if the radiological criterion is associated with at least one clinical criterion

Fig. 1. Modified New York criteria for ankylosing spondylitis (AS). 
abnormalities in x-ray images. To be more specific, axial spondyloarthritis is diagnosed if 1) distinctive findings of radiological examinations (including simple radiological examinations and/or MRI) with more than one clinical symptoms of spondyloarthritis or 2) more than two clinical symptoms are present in HLA-B27-positive patients (Fig. 2). The term "axial spondyloarthritis" includes ankylosing spondylitis (the most common type), reactive arthritis, psoriatic arthritis, and spinal arthritis (which accompanies inflammatory colitis).

\section{The Goal of Treatments}

The progress of ankylosing spondylitis varies; however, 1/3 patients progress with serious disability. In the early stage of the disease, back pain and ankylosis are often found as well as a limitation of chest expansion and reduction in the motion range of the spine, which cause occupational disability and direct or indirect economic burden ${ }^{4}$. The objectives of treatment are 1) alleviation of pain, 2) recovery of physical functions related to daily life and occupational activities, and 3) delay of structural damage responsible for physical impairments.

\section{1) Physical therapy and education}

The most important component of non-drug treatments of ankylosing spondylitis is education of patients and regular exercise. Although home exercise is known to be effective, group physical therapy under appropriate supervision is more efficient than individual exercise $^{6}$. It is important to educate patients that proper exercise not only alleviates pain but also relaxes the joints so that daily life activities are not affected.

\section{2) Medications}

(1) Nonsteroidal anti-inflammatory drugs (NSAIDs)

NSAIDs including the Coxib class are the first-line drugs for ankylosing spondylitis. A recent study reported that ankylosing spondylitis is associated with the prostaglandin E receptor 4 (PTGER4) gene. This receptor is associated with bone absorption; NSAIDs inhibit prostaglandin production, thus reducing the absorption $^{12)}$.

It is difficult to choose the best NSAID agent since responses and therapeutic potency vary between patients. Although it has been controversial which administration method is the most effective, it is now generally accepted that the drugs should be administered

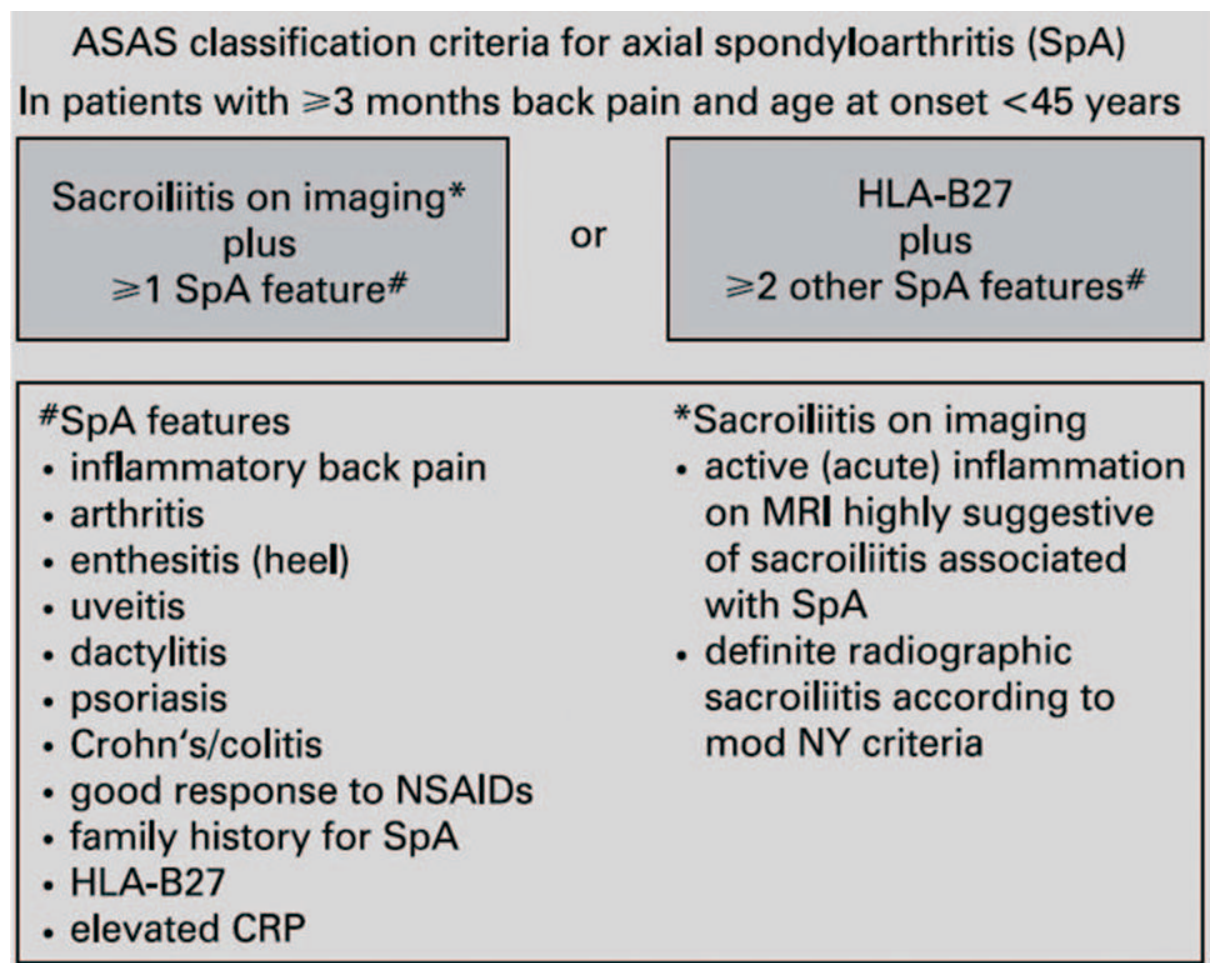

Fig. 2. ASAS classification criteria for axial spondyloarthritis.

ASAS: ASsessment of Ankylosing Spondylitis, NSAIDs: nonsteroidal anti-inflammatory drugs, HLA-B27: human leukocyte antigen B-27, CRP: C-reactive protein, mod NY criteria: modified New Yoirk criteria. 
continuously. This view is supported by the finding that the group with continuous medication presented better clinical outcomes in terms of disease progression (i.e., less new bone formation) than the group in which patients were taking the drugs only when they experienced pain ${ }^{13}$.

It is important to note that there are several complications of NSAIDs, in particular related to the cardiovascular system as well as gastrointestinal and renal complications. However, patients with symptoms not related to joints (e.g., inflammatory gastrointestinal disorders) may be treated with the selective COX-2 inhibitors without risk of complications ${ }^{14}$.

It is possible to use two different types of NSAIDs within the maximum allowed dosage over at least 4 weeks, but no specific regulations are available for the duration of each NSAID. For instance, it is possible to use NSAID A for a week and replace it with NSAID B for the remaining 3 weeks; similarly, one NSAID can be used for 2 weeks and another one for the following 2 weeks.

If the Bath ankylosing spondylitis disease activity index (BASDAI) is higher than 4 even after NSAID treatment (i.e, no improvement in symptoms), other agents such as TNF- $\alpha$ inhibitors should be considered ${ }^{(}$(Fig. 3).

\section{(2) Analgesics}

Acetaminophen and opioid-(like) agents are often used 1) for patients who complain of pain even after administration of NSAIDs and TNF- $\alpha$ inhibitors or 2) when other therapeutic options are not available.

\section{(3) Glucocorticoids}

Although local glucocorticoid injection can be considered for skeletal muscle inflammation such as enthesitis, systematic administration of steroids is not generally recommended ${ }^{6}$.

(4) Disease-modifying anti-rheumatic drugs (DMARDs) Although the administration of DMARDs (e.g., sulfasalazine and methotrexate) is not recommended for axial diseases such as back pain, sulfasalazine is worth considering for treatment of peripheral arthritis ${ }^{6}$.

\section{(5) TNF- $\alpha$ inhibitors}

In 1995, Braun and coworkers ${ }^{15}$ isolated TNF- $\alpha$ from ankylosing spondylitis patients via sacroiliac arthrocentesis. Thus, it was recognized that TNF- $\alpha$ is an important inflammatory mediator in this disease, which dramatically facilitated the development of biological agents.

As many studies have demonstrated that TNF- $\alpha$ inhibitors are effective for treatment of not only advanced ankylosing spondylitis, but also its early stage, early use of TNF- $\alpha$ inhibitors has been recommended ${ }^{2-6,10,11)}$. The ASAS guidelines (first released in 2006) recommended to use them for patients who had been diagnosed with ankylosing spondylitis according to the New York criteria and treated with more than two NSAIDs over 3 months. Yet, in the updated ASAS guidelines (2010), axial spondyloarthritis was included in addition to the New York criteria. Furthermore, it was recommended to use the TNF- $\alpha$ inhibitors in cases where more than 2 types of NSAIDs are administered over 4 weeks ${ }^{6}$.

So far, infliximab, etanercept, and adalimumab have been used in South Korea. In the present review, we introduce the dosing methods for clinical applications of these three agents on the basis of recently reported longterm follow-up studies ${ }^{16-19}$.

In the following we introduce some principles of application of TNF- $\alpha$ inhibitors.

1. Even though there is no difference in potency of various TNF- $\alpha$ inhibitors against musculoskeletal system symptoms in ankylosing spondylitis, monoclonal antibodies (infliximab and adalimumab) have been found to be more effective for gastrointestinal symptoms than receptor blockers (etanercept).

2. If one agent is not effective, it can be replaced with other agents.

3. Responses to biological agents should be evaluated at least 12 weeks after administration.

4. Favorable outcomes of treatment with TNF- $\alpha$ inhibitors are expected if 1) duration of symptoms is short and 2) the result of C-reactive protein examination is positive.

5. Latent tuberculosis should be examined before administration since some reports indicate that the incidence rate of tuberculosis is elevated due to TNF- $\alpha$ inhibitors ${ }^{20)}$.

\section{Infliximab (Remicade)}

Infliximab is a chimeric monoclonal antibody against TNF- $\alpha$ and is the first developed biological agent, consisting of $75 \%$ of human and $25 \%$ of mouse sequences ${ }^{16}$. This antibody directly binds to TNF- $\alpha$ and neutralizes it. It is administered by intravenous injections at $5 \mathrm{mg} / \mathrm{kg}$ body weight. For the first administration, the 


\section{Hip \& Pelvis}

Kyoung-Ho Moon et al. Medical Treatment of Ankylosing Spondylitis

same dose of infliximab is injected twice with an interval of 2 weeks and then the drug is administered every 6 weeks. Baraliakos et al. ${ }^{16)}$ reported a drug survival rate (patients who completed 8 years of treatment) of $48 \%$ and $88 \%$ of partial remission or low disease activity after 8 -year follow-up. It was also reported that the potency was similar when the treatment was interrupted for 3 years and then resumed. In addition, the authors reported that responses after the first 12 weeks of treatment could be used as a prognostic factor for clinical outcomes after 8 years. Finally, it was claimed that the stability of the antibody was not an issue of concern.

\section{Etanercept (Enbrel)}

Etanercept is a soluble blocker of TNF- $\alpha$. This fusion protein binds TNF- $\alpha$, which hinders interactions between TNF- $\alpha$ and TNF- $\alpha$ receptor located on other cells. Etanercept is generally administered by subcutaneous injection of $25 \mathrm{mg}$ twice a week ${ }^{17,18)}$. Martín-Mola et al. ${ }^{17)}$ reported that $63 \%$ of the enrolled patients completed 5 years of etanercept administration without any serious complications, while Baraliakos et al. ${ }^{18)}$ reported a drug

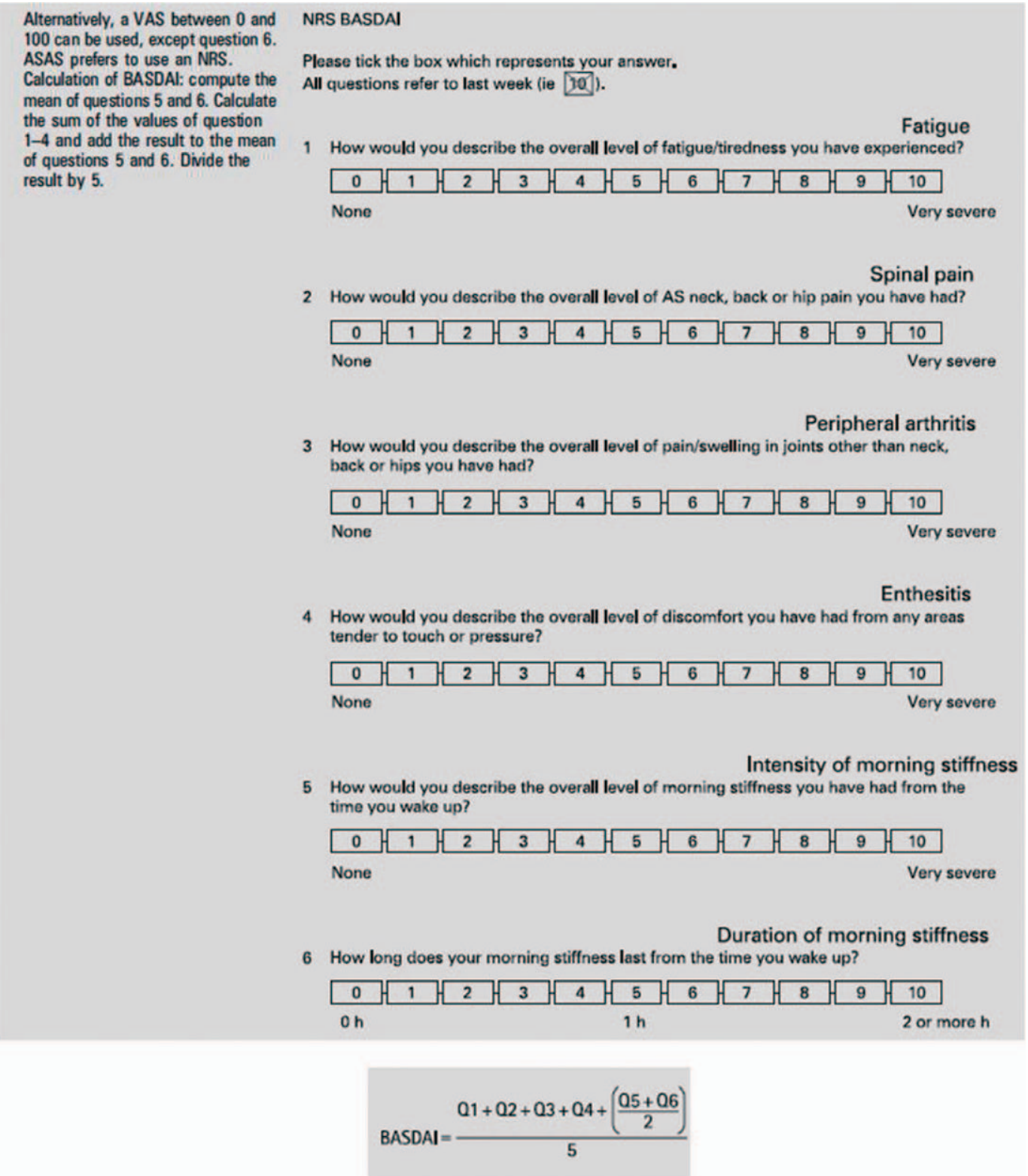

Fig. 3. Numerical rating scale of Bath Ankylosing Spondylitis Disease Activity Index (BASDAI).

VAS: visual analogue scale, ASAS: ASsessment of Ankylosing Spondylitis, NRS: numeric rating scale, AS: ankylosing spondylitis. 
survival rate of $62 \%$, partial remission in $31 \%$ of patients, and complete remission in $44 \%$ of patients in a 7 -year follow-up study. Similar to infliximab, etanercept was effective when medication was interrupted and then resumed; the drug survival rate was slightly higher in the etanercept group than in the infliximab group.

\section{Adalimumab (Humira)}

Like infliximab, adalimumab is a monoclonal antibody against TNF- $\alpha$ but its sequence is $100 \%$ human. Adalimumab is administered by subcutaneous injections of $40 \mathrm{mg}$ once per 2 weeks. Sieper et al. ${ }^{19)}$ reported a drug survival rate of $65 \%$, partial remission according to Ankylosing Spondylitis Disease Activity Score (ASDAS) in $51 \%$ of patients, and ASDAS inactive disease in $61 \%$ of patients in a 5-years follow-up study. Similar to the long-term follow-up results for infliximab, favorable outcomes of long-term follow-up were demonstrated with remission achieved after 12 weeks of administration.

Although there is no alternative option available if TNF- $\alpha$ inhibitors are not effective, other biological agents such as inhibitors of inflammatory cytokines (e.g., interleukin [IL]-1 and IL-6) have been actively investigated $^{21)}$.

\section{3) Duration of medications}

The optimal duration of ankylosing spondylitis treatment with NSAIDs and TNF- $\alpha$ inhibitors is still controversial. According to the recommendations of ASAS published in 2010, continuous administration of NSAIDs is recommended only when the disease is persistently active or symptomatic, but the same paper suggested that continuous treatment would be more effective for prevention of new bone formation than ondemand treatment ${ }^{6}$. A recent review reported no significant difference in safety and efficacy between ondemand and continuous administration of NSAIDs against inflammatory arthritis, but further investigations are warranted ${ }^{22}$.

Long-term follow-up studies have reported no noticeable difference in the potency of TNF- $\alpha$ inhibitors when they were administered continuously or intermittently, suggesting the necessity of on-demand administration ${ }^{16,18)}$.

Overall, it seems reasonable to assess the benefits and risks of continuous administration of NSAIDs and TNF- $\alpha$ inhibitors. In particular, administration of TNF- $\alpha$ inhibitors may be discontinued for a certain period of time and then resumed. Such scheme might be useful under special circumstances, for example: 1) a patient wants to become pregnant, 2) a patient has been suffering from repetitive infections, and 3) a patient is about to have surgery ${ }^{22,23)}$.

\section{CONCLUSION}

Although there are limited options available for diagnosis and treatment of ankylosing spondylitis, early detection and treatment of this disease have been made possible by recent dramatic advances in diagnostic technologies and biological agents. Although surgical treatment is sometimes used, most ankylosing spondylitis patients are treated with medications at nonorthopedic departments. Overall, orthopedic surgeons should make more effort to reduce the economic burden of ankylosing spondylitis and alleviate patients' suffering from spinal and musculoskeletal pain and deformity via active diagnosis and treatment.

\section{ACKNOWLEDGEMENTS}

This study was supported by a research fund from Inha University.

\section{REFERENCES}

1.van Royen BJ, Dijkmans BAC. Ankylosing spondylitis: diagnosis and management. New York: Taylor \& Francis; 2006.

2.Zochling J, Maxwell L, Beardmore J, Boonen A. TNFalpha inhibitors for ankylosing spondylitis. Cochrane Database Systemic Rev. 2005;3:CD005468.

3. Khan MA. Update on spondyloarthropathies. Ann Intern Med. 2002;136:896-907.

4.Zochling J, van der Heijde D, Burgos-Vargas R, et al. 'ASsessment in AS' international working group; European League Against Rheumatism. ASAS/EULAR recommendations for the management of ankylosing spondylitis. Ann Rheum Dis. 2006;65:442-52.

5. Braun J, de Keyser F, Brandt J, Mielants H, Sieper J, Veys E. New treatment options in spondyloarthropathies: increasing evidence for significant efficacy of anti-tumor necrosis factor therapy. Curr Opin Rheumatol. 2001;13: 245-9.

6. Braun J, van den Berg R, Baraliakos X, et al. 2010 update of the ASAS/EULAR recommendations for the management of ankylosing spondylitis. Ann Rheum Dis. 2011;70:896-904.

7. Sieper J, Braun J, Rudwaleit M, Boonen A, Zink A. Ankylosing spondylitis: an overview. Ann Rheum Dis. 2002;61 Suppl 3:iiis-18.

8. Rudwaleit M, Metter A, Listing J, Sieper J, Braun J. 
Inflammatory back pain in ankylosing spondylitis: a reassessment of the clinical history for application as classification and diagnostic criteria. Arthritis Rheum. 2006;54:569-78.

9. Bennett AN, McGonagle D, O'Connor P, et al. Severity of baseline magnetic resonance imaging-evident sacroiliitis and HLA-B27 status in early inflammatory back pain predict radiographically evident ankylosing spondylitis at eight years. Arthritis Rheum. 2008;58:3413-8.

10. Haibel H, Rudwaleit M, Listing J, et al. Efficacy of adalimumab in the treatment of axial spondylarthritis without radiographically defined sacroiliitis: results of a twelve-week randomized, double-blind, placebo-controlled trial followed by an open-label extension up to week fiftytwo. Arthritis Rheum. 2008;58:1981-91.

11. Barkham N, Keen HI, Coates LC, et al. Clinical and imaging efficacy of infliximab in HLA-B27-Positive patients with magnetic resonance imaging-determined early sacroiliitis. Arthritis Rheum. 2009;60:946-54.

12. Evans DM, Spencer CC, Pointon JJ, et al. Interaction between ERAP1 and HLA-B27 in ankylosing spondylitis implicates peptide handling in the mechanism for HLAB27 in disease susceptibility. Nat Genet. 2011;43:761-7.

13. Wanders A, Heijde Dv, Landewé R, et al. Nonsteroidal antiinflammatory drugs reduce radiographic progression in patients with ankylosing spondylitis: a randomized clinical trial. Arthritis Rheum. 2005;52:1756-65.

14. El Miedany Y, Youssef S, Ahmed I, El Gaafary M. The gastrointestinal safety and effect on disease activity of etoricoxib, a selective cox-2 inhibitor in inflammatory bowel diseases. Am J Gastroenterol. 2006;101:311-7.

15. Braun J, Bollow M, Neure L, et al. Use of immunohistologic and in situ hybridization techniques in the examination of sacroiliac joint biopsy specimens from patients with ankylosing spondylitis. Arthritis Rheum. 1995;38:499-505.

16. Baraliakos X, Listing J, Fritz C, et al. Persistent clinical efficacy and safety of infliximab in ankylosing spondylitis after 8 years--early clinical response predicts long-term outcome. Rheumatology (Oxford). 2011;50:1690-9.

17. Martín-Mola E, Sieper J, Leirisalo-Repo M, et al. Sustained efficacy and safety, including patient-reported outcomes, with etanercept treatment over 5 years in patients with ankylosing spondylitis. Clin Exp Rheumatol. 2010;28:238-45.

18. Baraliakos X, Haibel H, Fritz C, et al. Long-term outcome of patients with active ankylosing spondylitis with etanercept-sustained efficacy and safety after seven years. Arthritis Res Ther. 2013;15:R67.

19. Sieper J, van der Heijde D, Dougados M, Brown LS, Lavie F, Pangan AL. Early response to adalimumab predicts long-term remission through 5 years of treatment in patients with ankylosing spondylitis. Ann Rheum Dis. 2012;71:700-6.

20. Khalessi AA, Oh BC, Wang MY. Medical management of ankylosing spondylitis. Neurosurg Focus. 2008;24:E4.

21. Bruner V, Atteno M, Spanó A, Scarpa R, Peluso R. Biological therapies for spondyloarthritis. Ther Adv Musculoskelet Dis. 2014;6:92-101.

22. Adams K, Bombardier C, van der Heijde D. Safety and efficacy of on-demand versus continuous use of nonsteroidal antiinflammatory drugs in patients with inflammatory arthritis: a systematic literature review. J Rheumatol Suppl. 2012; $90: 56-8$

23. Baraliakos X, Listing J, Brandt J, et al. Clinical response to discontinuation of anti-TNF therapy in patients with ankylosing spondylitis after 3 years of continuous treatment with infliximab. Arthritis Res Ther. 2005;7: R439-44. 